\title{
ERRATUM: Caveolin-1 Modulates Docetaxel-Induced Cell Death in Breast Cancer Cell Subtypes through Different Mechanisms
}

\author{
Jinho Kang, BS', Joo Hee Park, MD¹, Hye Jin Lee, BS ${ }^{1}$, Ukhyun Jo, PhD'1, Jong Kuk Park, PhD², Jae Hong Seo, MD, PhD', \\ Yeul Hong Kim, MD, PhD'1, Insun Kim, MD, PhD³, Kyong Hwa Park, MD, PhD' \\ ${ }^{1}$ Division of Oncology/Hematology, Department of Internal Medicine, Korea University College of Medicine, Seoul, \\ ${ }^{2}$ Division of Radiation Cancer Biology, Korea Institute of Radiological and Medical Sciences, Seoul, \\ ${ }^{3}$ Department of Pathology, Korea University College of Medicine, Seoul, Korea
}

Correction to: Cancer Res Treat. 2016 Apr;48(2):715-726; http:// doi.org/10.4143/ crt.2015.227

For the data represented in Fig. 4B, we have generated a new figure from one of these repeat experiments. The experiments were done using the same cells, and antibodies according to our laboratory's standard operating procedures and the experiments were performed by the same individual. As the figure shown, these data do not change the outcome of the original paper. The correct version of the figure is below.

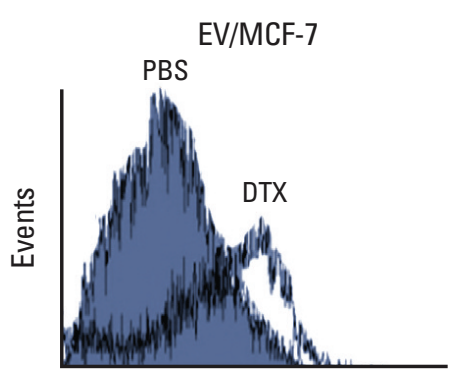

FL1-H
CAV-1/MCF-7

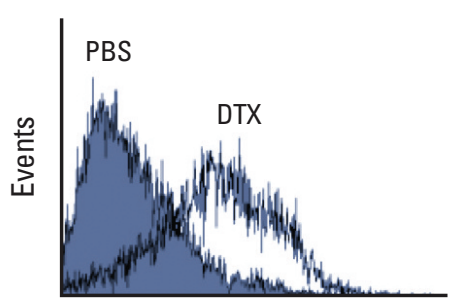

FL1-H

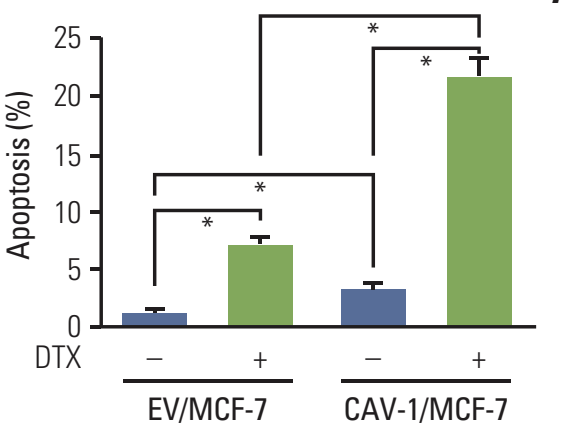

B

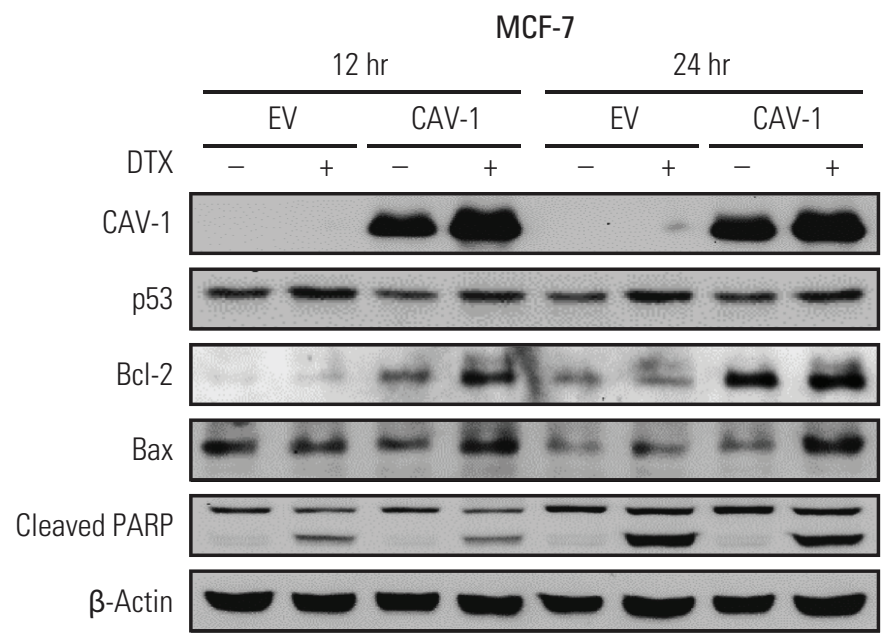

